\title{
Progressive backfill mining technology with split and two wings
}

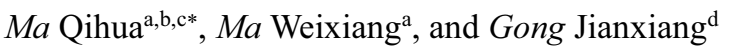 \\ ${ }^{a}$ College of Energy and Mining Engineering, Shandong University of Science and Tech- \\ nology, Qingdao 266590, China \\ bNational Experimental Teaching Demonstration Center of Mining Engineering, Shandong \\ University of Science and Technology, Qingdao 266590, China \\ 'State Key Laboratory of Mine Disaster Prevention and Control, Shandong University of \\ Science and Technology, Qingdao 266590, China \\ ${ }^{\mathrm{d}}$ Shandong Energy Xinwen Mining Group, Taian,271000, China
}

\begin{abstract}
With the large-scale development of the mining industry, soil and water loss, environmental pollution and other geological disasters accompanied by coal mining are continually increasing. Therefore, while promoting coal mine production by relying on scientific and technological progress, measures to control and reduce the resulting disasters cannot be ignored. In this paper, taking Xiezhuang coal mine as an example, we have combined its actual production conditions to solve the environmental problems caused by the massive accumulation of surface gangue in Xiezhuang coal mine. Moreover, to improve the efficient recovery of coal resources and ensure the safety of deep resources mining, and to reduce the rock burst and the damage caused to the underground water body, a research on forward filling mining technology with split-wing is put forward. This paper mainly discusses the related technologies and laws of forward filling mining method with split-wing, coal mining system, technological process, and filling mining.
\end{abstract}

\section{Introduction}

The increased production and living standards of human beings will gradually change the original appearance of nature. This in turn exceeds the purification ability of nature itself further leading to ecological damage, and thus affecting the normal environment. In addition to the damage caused to the natural interface, mine exploitation always emits various gases, smoke, mineral and metal dusts, and other harmful substances that results in environmental pollution and water cycle attenuation, which further aggravates the "greenhouse effect" and global warming, ozone shield deterioration, sharp decline of forests, species

\footnotetext{
*Corresponding author: skdrcb@sdust.edu.cn
} 
extinction, shortage of freshwater resource, etc. To maintain the balance between ecology and environment, our country has put forward the 32-word policy that focuses on prevention, by performing "comprehensive planning and utilization, rational layout, by converting loss into profit, relying on the masses, everyone's hands, protecting the environment and benefiting the people," to standardize the activities of human production and life.

The development of coal mining has led to conditions such as draining of mine water and open pit water, rise in the amount of gangue dust, production of harmful gases, surrounding rock deformation, and surface subsidence. All of these have obviously damaged the hydrogeology, engineering geology, atmosphere, and land conditions of the mining area by forming hundred square kilometers of surface subsidence pits. These pits cause the shallow flow of water, disappearance of rivers, and drying and salinizing of soils. While promoting coal mining by relying on scientific and technological progress, it is imminent to control the disasters caused by the coal production and realize the harmonious development of human and nature.

In this study, we have combined the actual production conditions of Xiezhuang coal mine to solve the environmental pollution and damage caused by a large number of gangue on the ground of Xiezhuang coal mine, and to improve the efficient recovery of coal resources by ensuring the safety of deep resource mining, and reducing the impact of ground pressure and damage caused to the underground water. In this paper, we have put forward the idea of "progressive backfill mining technology with split two wings." The research of this subject can not only bring several economic benefits to the enterprise, but also promote the sustainable development of coal enterprises and the establishment of a harmonious society.

\section{Research on the technology system of split and two wings forward filling mining}

\subsection{Feasibility and rationality of forward filling mining system with two wings in different directions}

To reduce the damage that underground mining causes to the surface, measures such as gangue exploitation, reducing the pollution caused by the gangue to the surface environment, and promoting the replacement of mining technology of gangue for coal must be implemented. For realizing this through research, it was decided to adopt a method for filling up the goaf with gangue for mining in 3414 working face of the mine. Due to the interaction between production and filling process of gangue filling mining method, the production efficiency was relatively low. To reduce the influence of the above factors, a double wing mining method was adopted. In this method, the boundary line was set $8 \mathrm{~m}$ to the west of the downhill of the track in the 4-3-3 mining area, and the two filling working faces in the east and west directions were arranged in a balanced way in the back direction for mining at the same time. After $8 \mathrm{~m}$ of push mining and filling in the west working face, the east working face was arranged along the goaf to perform push mining across the 4-3-3 mining area track down the mountain and belt down the mountain, and push through and push through the mountain with the return air of the mining area. The two working faces shared a shunting, tipping, and storage bin system. Two between $20 / 80$ emulsion pumps that arch liquid on both sides at the same time, which can reasonably match the construction personnel to organize production, occupy less personnel and have high work efficiency. It has the characteristics of one area, two sides, one filling, one accurate filling or two filling. This mining method not only reduces the number of cut holes and the amount of work, but also greatly improves the production efficiency. Therefore, this mining method is tech- 
nically feasible and economically reasonable.

\subsection{General situation of filling mining face}

The design of - 550 level 4-3-3 mining area was approved by Xinkuang group's No. 95 document on September 8, 1996, and the mining area started its production in 1997. The mining area is a double wing mining area that adopts the joint layout of two and four floors. The layout includes - 550 level 4-3-3 mining area in the downhill track, transportation downhill, and return air downhill with the help of 4-3 main return lane for return air.

3414 filling working face is located at the top of the west wing of the fourth coal seam in the 4-3-3 mining area of - 550 level by arranging 3414w and 3414e filling working faces. The layout of the working face roadway is depicted in Figure 2.1.

(1) 3414w filling working face

The working face is located at the top of the west wing of the fourth coal seam in 4-3-3 mining area of - 550 level to the boundary of - 550 auxiliary shaft protective coal pillar in the south with an elevation of approximately - 557 to $-560 \mathrm{~m}$, to the old goaf protective coal pillar of $3415 \mathrm{w}$ working face in the north with an elevation of approximately - 590 to $595 \mathrm{~m}$, to the cut of $3414 \mathrm{w}$ filling working face in the east, and to the stopping line of $3414 \mathrm{w}$ filling working face in the west. The working face is $234 \mathrm{~m}$ long from east to west, $92 \mathrm{~m}$ wide from north to south with an area of $21528 \mathrm{~m}^{2}$ and a recoverable reserve of 76921.7 t. The corresponding ground elevation of the working face is $+163.17 \mathrm{~m}$. (2) 3414 e filling working face

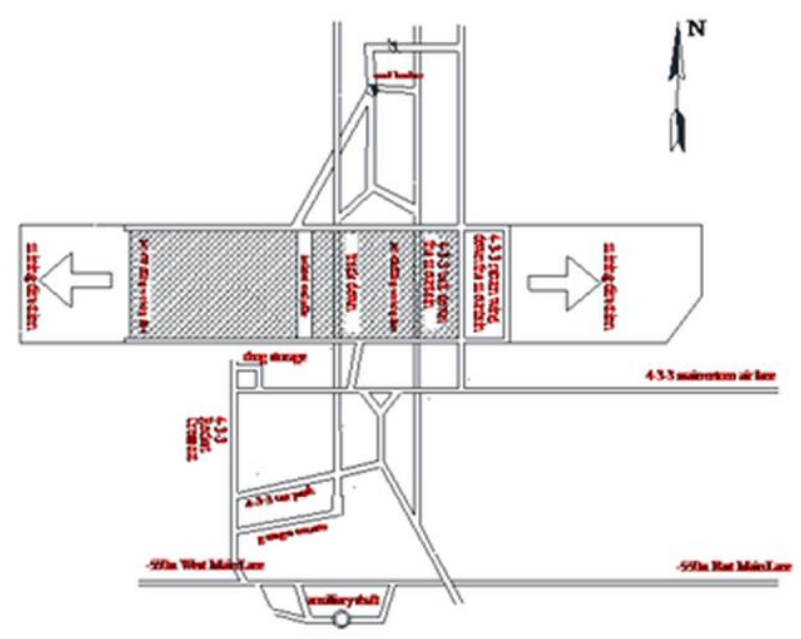

Fig 2.1. Layout of roadway in filling mining face.

This working face is located at the top of the east wing of the four coal layers in the 4-3-3 mining area of - 550 level to the boundary of - 550 auxiliary shaft protective coal pillars in the south with an elevation of approximately - 558 to $-561.4 \mathrm{~m}$, to the old goaf protective coal pillars in the $3415 \mathrm{E}$ working face in the north with an elevation of approximately 590.4 to $-592 \mathrm{~m}$, to the cut-out of the $3414 \mathrm{e}$ filling working face in the west, and to the stoppage line of $3414 \mathrm{e}$ filling working face in the east. The average length of the working 
face is $278 \mathrm{~m}$ in the east-west direction, $97 \mathrm{~m}$ in the north-south direction, an inclined area of $26966 \mathrm{~m}^{2}$, and $97107 \mathrm{t}$ in the recoverable reserves. The corresponding ground elevation of the working face is $+163.17 \mathrm{~m}$. When the upper roadway and the lower roadway of the working face were pushed and mined for $5 \mathrm{~m}$ and $10 \mathrm{~m}$ respectively, they were pushed and mined down the mountain across the track of 4-3-3 mining area, and 17.2-18.2 $\mathrm{m}$ away from the rock pillar of the track of 4-3-3 mining area, respectively. When the upper roadway was pushed $35 \mathrm{~m}$ and the lower roadway was pushed $41 \mathrm{~m}$, they were pushed down the mountain across the belt of 4-3-3 mining area, 9.6-14.6 m away from the rock pillar of 4-3-3 mining area. When the upper roadway was pushed $46 \mathrm{~m}$ and the lower roadway was pushed $55 \mathrm{~m}$, they were pushed through and pushed through with the return air of 4-3-3 mining area. When the upper roadway was pushed $78 \mathrm{~m}$ and the lower roadway was pushed $87 \mathrm{~m}$, they were pushed through with the east cut hole of the face.

\subsection{Forward filling system with two wings and filling technology}

\subsubsection{Filling system of 3414 filling mining face}

\section{1) Gangue transportation system}

The gangue at - 550 level and - 850 level were transported to - 550 level 4-3-3 mining area using a $1 \mathrm{t}$ tramcar. A 20 -m parking lot was set up in the main return air lane, in which 8 gangue trucks could be parked at a time. The shunting was conducted using a $5 \mathrm{t}$ battery car, and the way of surrounding in and out will be adopted. A self-made 1t dumper was installed in front of the parking lot, and a $314 \mathrm{~m}^{3}$ inclined gangue bin was set in front of the dumper as the gangue buffer.

(1) Inside the car

The battery car drives into the main lane through the turnout $1 \rightarrow$ the battery car is in the off track of the outer yard, and the gangue car group (the number of groups shall not exceed 12 vehicles / time) passes through the 4-3-3 mining area track and goes down the rope track, then, it passes through the two air doors (after the working face is pushed and mined, the upper air is changed to the lower air after the ventilation system is adjusted, and the two air doors are removed), and thereafter, the gangue car is taken through the turnout 2 and $3 \rightarrow$ the turnout 3 is transferred to the straight track, and the overhead car of the battery passes through the turnout 4 to in front of the dumper $\rightarrow$ manually push the gangue truck into the dumper and unload.

(2) Outside the car

After unloading six cars, the battery car passes through the turnouts 3 and 2, and the turnouts and the car body are set at the turnouts $2 \rightarrow$ the car passes through the damper, the turnouts 1 and 4-3-3 mining area track and goes down the mountain to the upper yard $\rightarrow$ the ore car is pushed to the outside yard.

The gangue transportation system of 3414 filling mining face is depicted in Figure 2.2. 


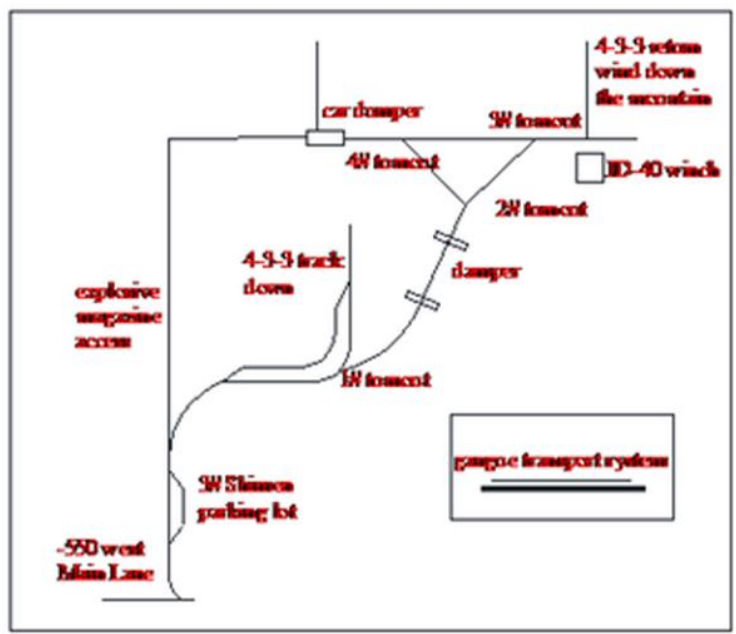

Fig 2.2. Schematic of gangue transportation system of 3414 in filling mining face.

\subsubsection{Filling technology of 3414 filling mining face}

3414 working face was filled with a special strong small belt throwing gangue machine loaded by an inverted belt or a slide, and thereafter, the roof was connected manually. When the top distance of push mining control of working face reached $8.3 \mathrm{~m}$, filling started in four intervals near the goaf. The filling sequence was from the bottom to the top along the inclined direction of working face, and the gangue conveying chute or belt was shortened rapidly from bottom to top, and the support was withdrawn along with the filling. To improve the filling capacity of the working face, the filling process was optimized at the same time of the filling construction. The results showed that "see seven filling four" was implemented in the $3414 \mathrm{w}$ filling working face, and "see six filling four" was implemented in the 3414 e filling working face.

\section{Relevant laws of gangue filling and mining}

\subsection{Ground pressure appearance and surface subsidence law of gangue fill- ing of stope}

\subsection{Crushing, swelling, and compaction characteristics of gangue}

According to the actual measurement of the gangue filling working face in Xinwen mining area, the distance between the common gangue filling and the empty top was approximately $0.2-0.3 \mathrm{~m}$. The actual average mining height of 3414 filling mining face in Xiezhuang coal mine was $2.75 \mathrm{~m}$. According to the theory, its equivalent mining height was approximately $0.37-0.97 \mathrm{~m}$, i.e., the medium thick coal seam with $2.75 \mathrm{~m}$ filling mining height was only equivalent to the thin or extremely thin coal seam of approximately $0.37-0.97$. 
Therefore, the law of mine pressure and surface subsidence in the general gangue filling mining would be significantly different from the same non-filling mining.

\subsubsection{Characteristics of mine pressure law in stope}

The results of the actual measurement and comparison of the general mining pressure of filling with gangue and filling with similar conditions (non-filling) in Xinwen mining area are listed in Table 3-1.

Table 3-1. Comparison between filling mining with gangue and filling mining with similar conditions (non-filling).

\begin{tabular}{|c|c|c|c|}
\hline \multicolumn{2}{|c|}{ Comparison of items } & \multirow{2}{*}{\begin{tabular}{c}
$\begin{array}{l}\text { Filled sur- } \\
\text { face }\end{array}$ \\
\multicolumn{1}{c}{13.5}
\end{tabular}} & \multirow{2}{*}{$\begin{array}{c}\begin{array}{c}\text { Unfilled } \\
\text { surface }\end{array} \\
12.5\end{array}$} \\
\hline Strut resistance / t & AVG & & \\
\hline (2) & MAX & 16.8 & 17.3 \\
\hline \multirow{2}{*}{$\begin{array}{c}\text { Roof subsidence / } \\
\text { mm }\end{array}$} & AVG & 42.5 & 159.3 \\
\hline & MAX & 59.8 & 186.2 \\
\hline \multirow{2}{*}{$\begin{array}{l}\text { Roof sinking speed } \\
\qquad /(\mathbf{m m} / \mathbf{h})\end{array}$} & AVG & 0.02 & 3.79 \\
\hline & MAX & 0.07 & 9.80 \\
\hline \multirow{2}{*}{$\begin{array}{l}\text { Influence range of } \\
\text { dynamic pressure / } \\
\text { m }\end{array}$} & AVG & 10.1 & 25.3 \\
\hline & MAX & 8.5 & 22.6 \\
\hline
\end{tabular}

It can be seen from the above table that the subsidence speed, subsidence amount, and the influence range of two roadway mining in the filling mining are significantly lower than those in the non-filling mining.

\subsubsection{Analysis of surface subsidence}

From the concept of equivalent mining height, the gangue filling mining can be regarded as the mining of extremely thin coal seam, and the traditional mine pressure theory and surface subsidence prediction can be used to analyze the strata pressure appearance and surface subsidence law in the gangue filling mining. This is a type of limit analysis method. The parameters such as pillar load, roadway deformation, supporting pressure, and surface deformation are all upper limit values, and the safety factor is assumed to be large.

From the theoretical analysis and the actual measurement comparison, we have come to the conclusion that after implementing gangue filling mining, the apparent intensity and absolute value of mine pressure in the stope could be significantly reduced.

\subsection{Numerical simulation and field observation of the damage depth of the bottom slab by filling}




\subsubsection{Numerical Simulation}

(1) Establishment of the model

This numerical simulation was based on the simplified geological conditions of 3414 filling face in Xiezhuang coal mine. Considering the influence of boundary effect with respect to the actual length $(90 \mathrm{~m})$ of the working face, the length $\times$ width $\times$ height of the model was calculated as $290 \times 200 \times 170 \mathrm{~m}$, and the schematic diagram of the model is depicted in Figure 3.1.

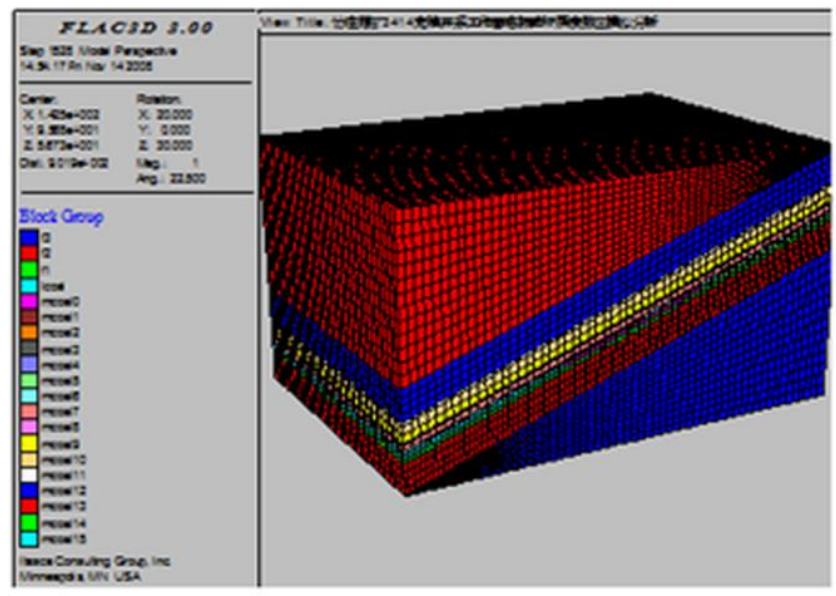

Fig 3.1. Model diagram

The numerical model consists of four boundaries. There was no displacement constraint on the upper boundary. Due to the limited size of the model, the simulation was difficult. Part of the overburden was applied to the upper boundary of the model similar to that of a uniform load, whose value was the self-weight of $680 \mathrm{~m}$ deep strata; the left and right boundary conditions of the model were set to limit horizontal displacement and allow vertical displacement; the lower boundary of the model was set to limit vertical displacement and horizontal displacement so that the nodes at the lower left and right corners of the whole model do not produce any displacement, thus ensuring that the model will not produce drift phenomenon during the calculation process.

(2) Simulation calculation process

In this model, excavation and filling were carried out gradually, i.e., at first $10 \mathrm{~m}$, after that $5 \mathrm{~m}$, and so on thereafter. Due to the limited size of the model, the model ends when the working face is pushed to $100 \mathrm{~m}$ and filled to $95 \mathrm{~m}$. Owing to several steps and figures, this simulation only picks the displacement, vertical stress and failure of the roof of the working face while mining the face at $20 \mathrm{~m}, 40 \mathrm{~m}, 60 \mathrm{~m}, 80 \mathrm{~m}$, and $100 \mathrm{~m}$, and filling the face at 15 $\mathrm{m}, 35 \mathrm{~m}, 55 \mathrm{~m}, 75 \mathrm{~m}$ and $95 \mathrm{~m}$. Due to space limitations, only the numerical simulation while mining at $20 \mathrm{~m}$ and filling at $15 \mathrm{~m}$ are depicted here. 

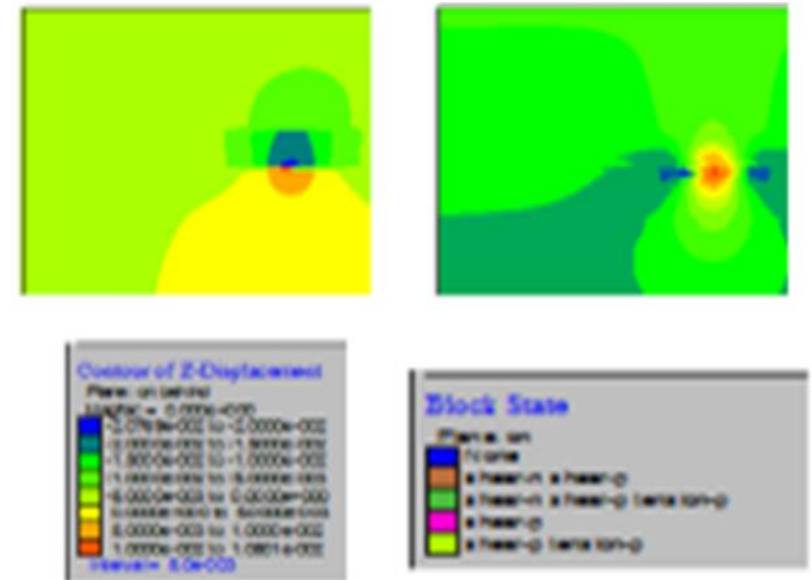

(a) Cloud map of vertical displacement distribution (b) Cloud map of vertical stress distribution
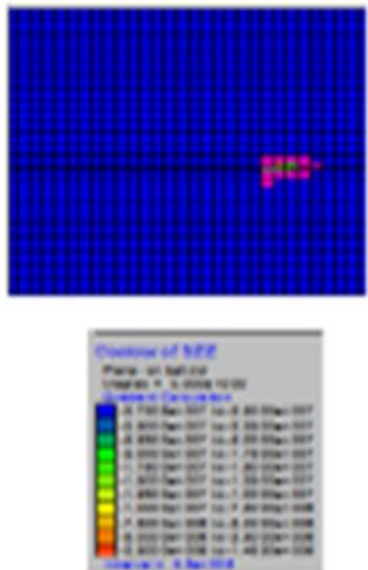

(c) Cloud map of plastic differentiation

Fig. 3.2. Roof and floor conditions along the strike of working face while mining at $20 \mathrm{~m}$.
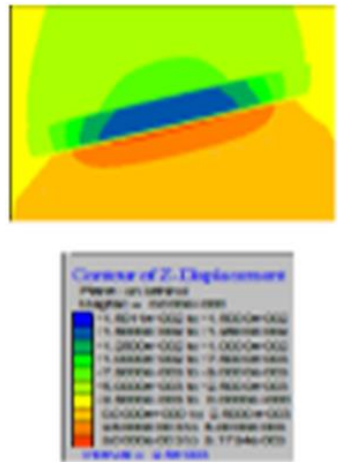
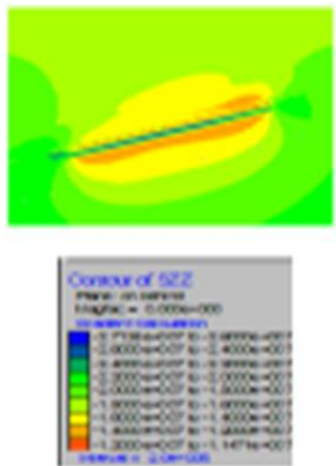
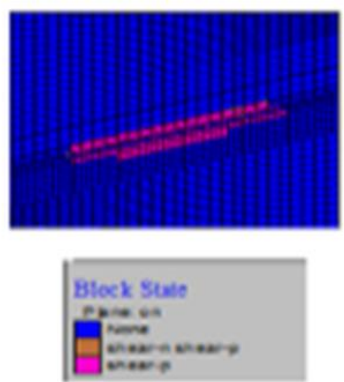

(a) Cloud map of vertical

displacement distribu-

(b) Cloud map of vertical stress distribution (c) Cloud map of plastic differentiation tion

Fig. 3.3. Roof and floor inclination along the working face while mining at $20 \mathrm{~m}$. 

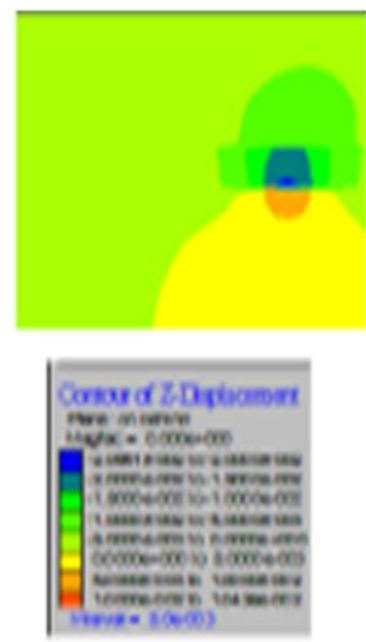

(a) Cloud map of vertical displacement distribution
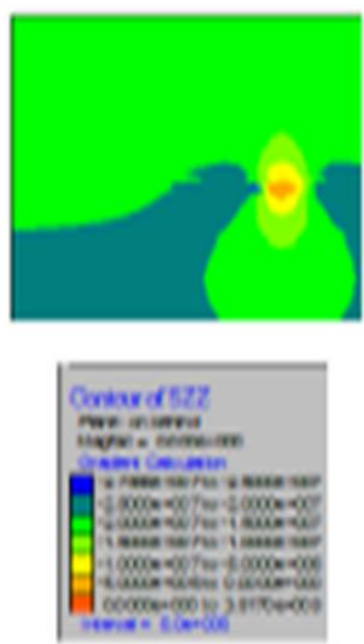
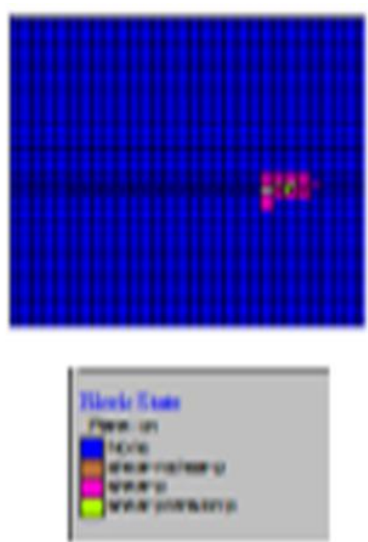

(c) Cloud map of plastic differentiation

Fig. 3.4. Top and bottom plate along the working face while filling at $15 \mathrm{~m}$.
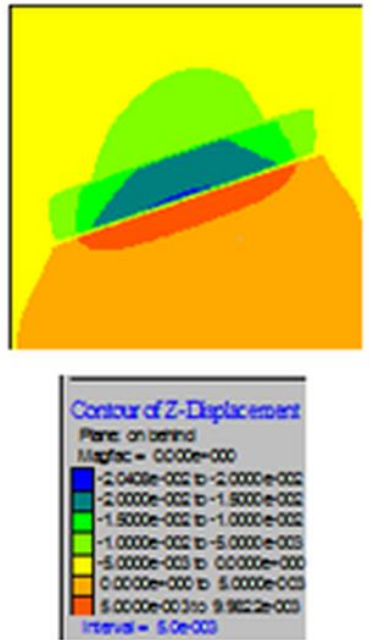

(a) Cloud map of vertical displacement distribution
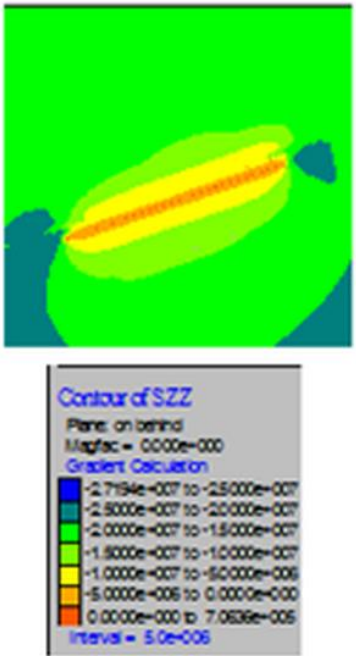

(b) Cloud map of vertical stress distribution
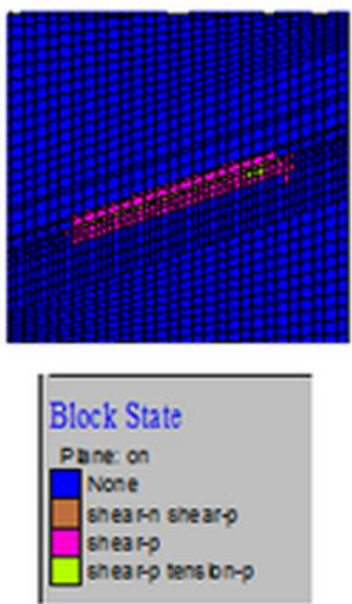

Fig. 3.5. Roof and floor inclination along the working face while filling at $15 \mathrm{~m}$. 


\subsubsection{Analysis of numerical simulation results}

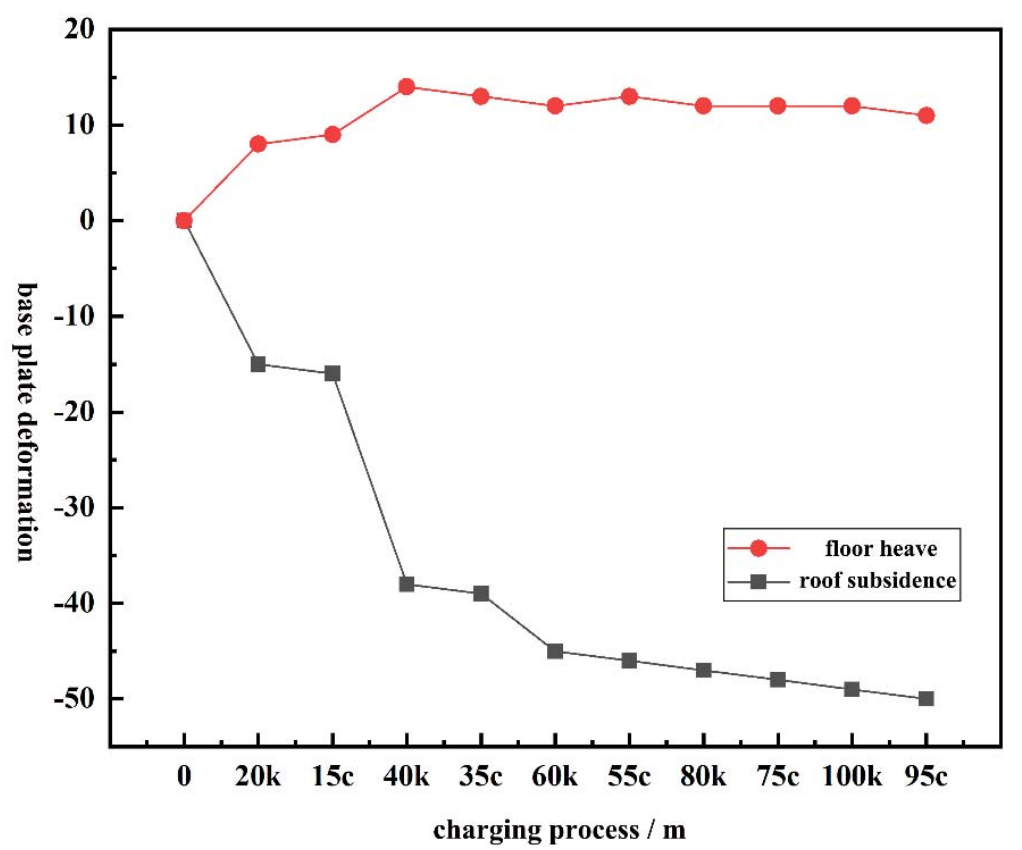

Fig 3.6. Deformation of top and bottom plates during excavation and filling.

From the numerical simulation of the excavation and filling process of the filling mining face, we could observe a sinking roof and a protruding floor during the initial stage of excavation and filling. Working face advanced in the range of approximately $15 \mathrm{~m}$, the maximum failure depth of the floor was approximately $3 \mathrm{~m}$. After that, the failure depth of the floor began to increase with respect to the forward advancement of working face, and the maximum failure depth was observed to be approximately $8 \mathrm{~m}$. The maximum failure depth was approximately $70 \mathrm{~m}$ during the middle of the working face, and was mainly manifested as shear failure. The maximum supporting pressure point was mainly concentrated in the range of approximately 5-13 m behind the cutting hole and in front of the coal wall. During the initial stage of face excavation and filling, the floor heave increased gradually with the advancement of the face, and decreased gradually with the advancement and filling of the face, thus increasing the roof subsidence and the compression of the filling body. The change curve of top and bottom plates in the middle of the working face with the excavation and filling process $20 \mathrm{~m}$ away from the cutting hole is depicted in Figure 3.6.

\subsubsection{Field observation of the depth of floor failure}

In this study, the depth of floor failure in the stope was measured in situ by using the "borehole double end plugging leak detector".

A suitable observation site around the working face was selected, and inclined holes were 
drilled down under the working face. Water was blocked and injected in sections along the borehole via water injection method, and the leakage flow of each section of the borehole was measured to understand the damage and looseness of the rock. Before mining in the working face, we studied the original fracture development law of the floor rock, and after mining in the working face, we studied and determined the damage depth of the coal seam floorОшибка! Источник ссылки не найден.

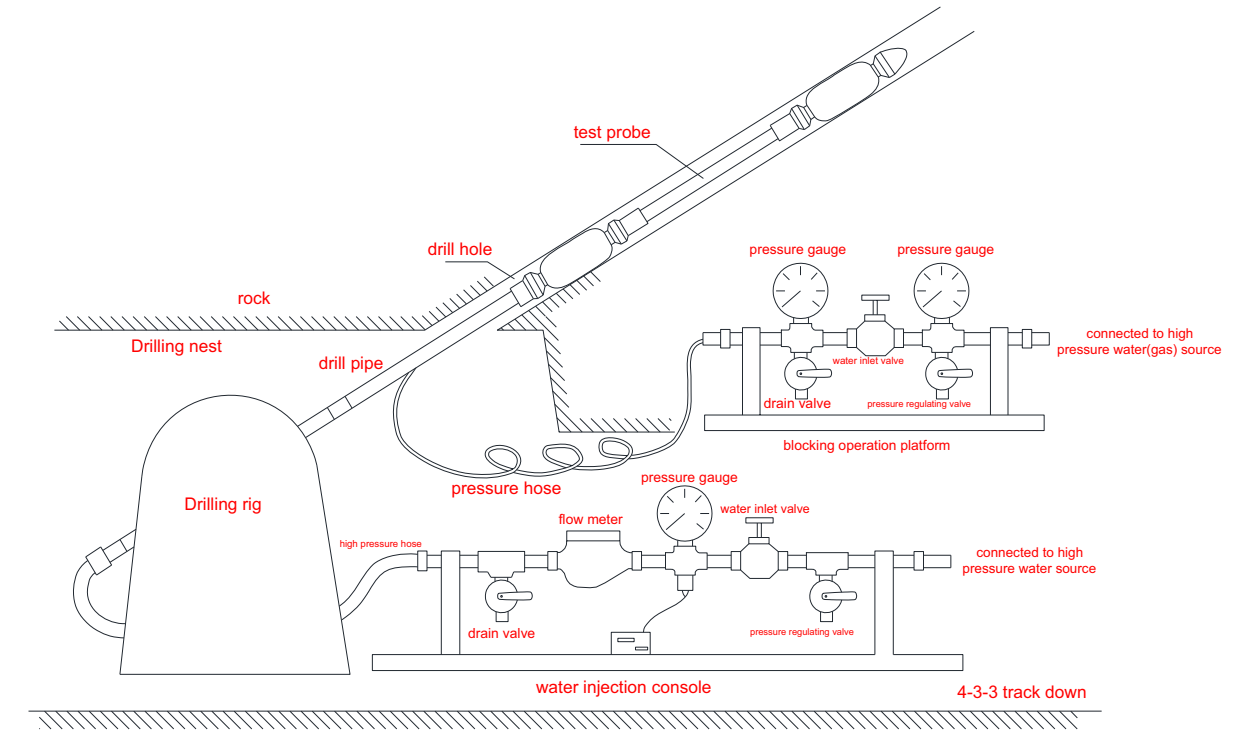

Fig. 3.7. Schematic of double end plugging leakage detection device.

According to the actual measurement under the condition of filling mining, the maximum damage depth of 3414 filling face floor in Xiezhuang coal mine was $7.3 \mathrm{~m}$.

\subsection{Analysis of the influence of filling mining on the height of roof fracture zone}

According to the cloud chart of each step, we could also simultaneously see the roof failure under the condition of filling mining. This section mainly simulates the failure of the roof and floor of the working face under the condition of non-filling mining (i.e., adopting the total caving method to manage the roof). From the comparative analysis of the numerical simulations of filling mining and non-filling mining, the following conclusions could be drawn:

Under the condition of non-filling mining, the damage of the floor starts from the two ends of the working face at first, and thereafter, with the continuous advancement of the working face, it continues from the opening toward the coal wall. When the failure reaches a certain degree, the failure rule changes, and it is no longer along the coal wall. However, it is from the opening to the middle of the coal wall, and thereafter, toward both sides of the wall. During filling mining, the failure of the floor starts from the coal wall, i.e., when the working face is pushed to a certain distance; the floor near the coal wall begins to deteriorate, and thereafter, along with the working face, we continue to push forward and develop for- 
ward and backward.

It was not difficult to calculate the maximum damage height of the roof and it was approximately $18 \mathrm{~m}$ (i.e. the height of the fracture zone), and the maximum damage depth of the floor was approximately $8 \mathrm{~m}$ when the full caving and gangue filling methods were used for comparing the numerical simulations. However, when the full caving method was used, the maximum damage height was more than $30 \mathrm{~m}$, and the damage depth of the floor was more than $13 \mathrm{~m}$. We observed that the filling method could effectively reduce the damage of the roof and floor, and it can effectively prevent the occurrence of water inrush accidents in the mine with water inrush risk, and it could also improve the upper limit of mining by extracting more coal resources and by reducing the waste of resources.

\section{Support technology of gob-side entry retaining in advance mining}

Until now, the technology of gob-side entry retaining in the face was mature, and the successful experience was obtained by using the anchor cable control cutting technology. The research on the technology of gob-side entry retaining in front of the filling work is very important to strengthen the recovery rate of coal, reduce the excavation rate of the roadway, ensure the excavation connection, improve the excavation rate, and improve the economic and social benefits of the mine's practical significance.

As the 3414-working face of Xiezhuang coal mine adopts the method of filling goaf to manage the roof, the production continuity is extremely tense. Therefore, it is atypical to carry out the progressive type, which is a new type of gob-side entry retaining technology, in the filling working face not only in Xinwen mining area, but also in the whole country. Therefore, it is necessary to study the front entry technology of filling work, to provide theoretical and on-site guidance for the gob-side entry retaining technology of similar mines.

\subsection{Control mechanism of surrounding rock in gob-side entry retaining technology}

According to the key layer theory in strata control, the key layer mainly refers to the old roof strata for the gob-side entry retaining. The "masonry beam" structure formed after its breaking will directly affect the stability of the gob-side entry retaining. The side support of the roadway must have a certain amount of shrinkage to reduce the pressure on the pillar. To maintain the integrity of the roadway roof and to reduce the subsidence of the roof, the side support of the roadway is required to have certain support resistance. Although the 3414-working face of Xiezhuang coal mine adopts the filling method to manage the goaf, because of the relatively cheap gangue(when the goaf is filled with gangue) the goaf will be soon compacted by the sinking roof. With the passage of time, the key layer and the direct roof gradually separate from each other. When the subsidence reaches a certain limit, the key layer breaks; however, the direct roof is filled with the lower gangue for the support of the body, and only bending and sinking occur. The key layer bears a relatively concentrated support pressure at a support point from breaking into "masonry beam". This will lead to serious fracture and deformation of the coal side. With the increase of the return angle of the key block, the roof of the roadway sinks sharply. The structural model of the surrounding rock of the roadway along the gob of the filling working face is depicted in Figure 4.1. 


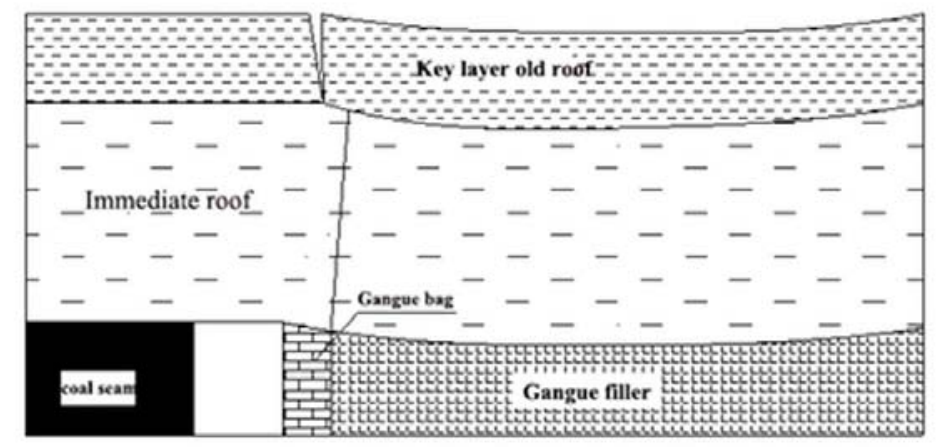

Fig 4.1. Surrounding rock structure model of gob-side entry retaining in filling face.

The deformation characteristics of the direct roof are very important for bolt support. The bolt does not have to bear the given deformation of the old roof rotation; however, it needs to adapt to the deformation characteristics of the direct roof. Controlling the displacement of the coal wall and the integrity of the roof above the side support of the roadway is the key to control the large deformation of the surrounding rock, and success of the roadway along the goaf.

At present, the following key technologies are mainly used to ensure the stability of surrounding rock in gob-side entry retaining.

(1) Reasonable design of filling body

The filling body mainly refers to the filling material of the side support along the goaf. The key factor of gob-side entry retaining is the selection of the material and performance of the gob-side entry retaining body along the gob, which requires fast resistance increasing speed, reasonable support resistance, the ability to cut down a certain height of the roof, the large amount of deformation to get adapted to the drastic deformation of gob-side entry retaining, and the hope that the cost of gob-side entry retaining is low. These characteristics promote the development of gob-side entry retaining technology ${ }^{0}$.

According to the observation of mine pressure and relevant data in 3414 filling face of Xiezhuang coal mine, it is shown that using gangue bag as the filling material of the side support of the roadway can not only meet the support requirements, but also achieve the purpose of consuming gangue.

(2) Reasonable support of roof

According to the roof condition of the working face, it is necessary to pre strengthen it by a reasonable combination of bolt and anchor net. Keeping the stability of roof coal is another key point of surrounding rock stability.

(3) Reasonable support of solid coal wall

The solid coal wall is the main bearing body of the gob-side entry retaining, and the fulcrum of the rotary subsidence of the key layer, which will cause the deformation of the surrounding rock to increase. Therefore, whether the support of solid coal wall is reasonable or not is directly related to the stability of surrounding rock of gob-side entry retaining.

(4) Reasonable reinforcement of roadway side angle

The stress concentration degree of the side angle of the roadway is high, which causes the roof to break and floor to heave. 


\subsection{Support design of gob-side entry retaining in $\mathbf{3 4 1 4}$ working face}

\subsubsection{Support design of gob-side entry retaining}

1) Roof support

The roof adopted a high-strength screw steel anchor rod, with a diameter of $20 \mathrm{~mm}$, length of $2000 \mathrm{~mm}$, and row spacing of $800 \times 900(\mathrm{~mm})$, and was equipped with a trapezoidal steel beam and a metal mesh. The form of roof reinforcement support was to install one row of anchor cable for every three rows of anchor bolts. There were two cables in each row, where the length of the anchor cable was $6.5 \mathrm{~m}$, and the row spacing was $2.7 \mathrm{~m}$. The anchor cable was equipped with a $14 \times$ channel steel belt with a length of $0.9 \mathrm{~m}$. The roof required the use of a double wing drill of $27 \mathrm{~mm}$ diameter to drill anchor holes of $28 \mathrm{~mm}$ diameter. One roll of z2535 type and one roll of z2550 type resin anchoring agent roll could be used for lengthening anchoring of each bolt. One roll of z2535 type and three rolls of z2550 type resin anchoring agents were used for extending the anchor cable.

2) Two groups of support

The two sides were provided with deformed steel bolts of high-strength, with diameter of $18 \mathrm{~mm}$, length of $2000 \mathrm{~mm}$ and row spacing of $600 \times 900(\mathrm{~mm})$, and were equipped with trapezoidal steel beam and metal mesh. Because the two sides of coal seam were soft, each bolt was lengthened and anchored with two rolls of z2550 resin anchoring agent to ensure its anchoring force. The top anchor bolts of the two sides were arranged at an elevation of $15^{\circ}$, the bottom anchor bolts were arranged at an elevation of $15^{\circ}$ (conducive to preventing floor heave), and the rest were arranged horizontally.

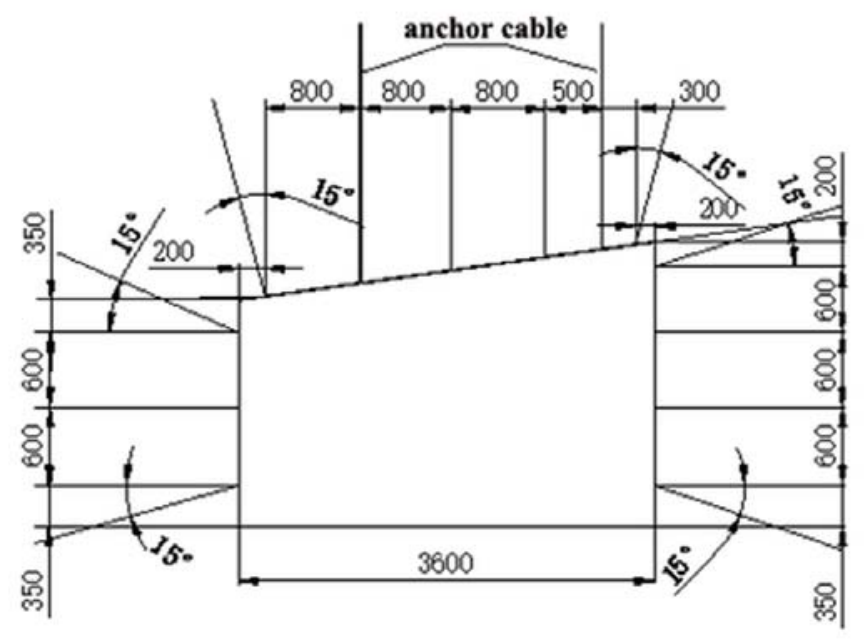

Fig 4.2. Schematic of anchor net support.

\subsubsection{Construction technology of gob-side entry retaining}

To control the destructive effect of the advance bearing pressure of the working face and 
pressure from the old roof on the surrounding rock of the roadway, and to ensure the safety and success of retaining the roadway, the construction should be carried out according to the following process:

(1) Within $10 \mathrm{~m}$ of the advance working face, two rows of "one beam and three columns" are erected (1.3 m and $2.3 \mathrm{~m}$ from the lower side), and within 10-40 m, one row of "one beam and three columns" is erected ( $2.3 \mathrm{~m}$ from the lower side). The props are made of single hydraulic props. The props must wear shoes, and the initial support force is not less than $50 \mathrm{KN}$. The beam is made of $2.2 \mathrm{~m}$-long $11 \times$ mining I-beam.

(2) Within $60 \mathrm{~m}$ behind the working face, a $2.2 \mathrm{~m}$-long I-shaped steel point post should be erected at every $450 \mathrm{~mm}$ along the strike at $3.2 \mathrm{~m}$ from the filling side of the lane to the lower side of the machine lane. The top shall be tightly wedged and a $200 \times 300 \times$ $500(\mathrm{~mm})$ wooden shoe should be worn at the bottom.
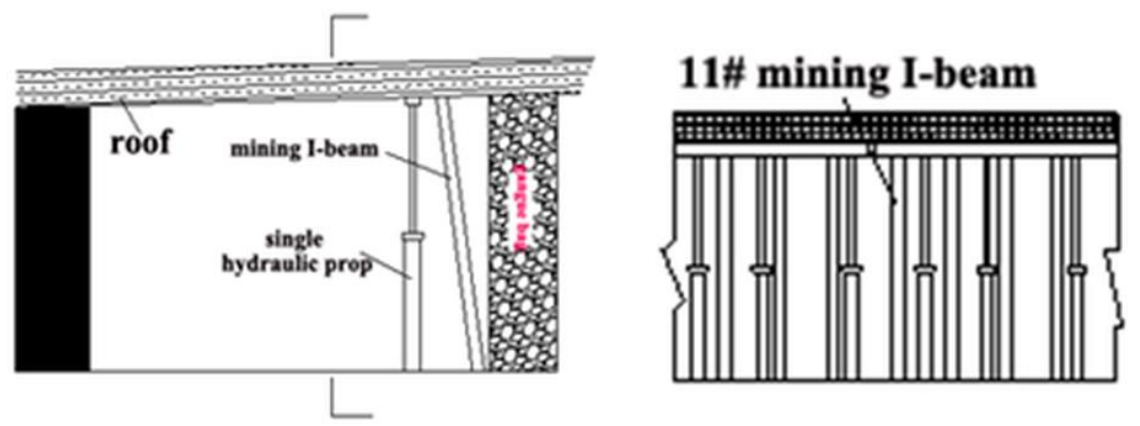

Fig 4.3. Construction scheme of gob-side entry retaining.

(3) After erecting the point column, the "one beam and three columns" trend shed should be erected along the strike at $100 \mathrm{~mm}$ from the top of the point column at the lower side of the machine lane.

(4) $1.0 \mathrm{~m}$ gangue belt should be built along the strike of I-beam point column foot, and $1100 \times 2000(\mathrm{~mm})$ injection mesh back should be used between the gangue belt and I-beam point column. Each shed point column should be evenly tied with 8-10 pond materials from top to bottom on the injection molding net along the direction.

(5) The gangue belt should be packed with plastic woven bags containing gangue or broken coal. The woven bags should be pressed in sequence, and the bottom line should be placed with I-steel point column foot. While building the roof, it should be filled with broken coal or sheet and the roof, and it is strictly prohibited to leave gaps in between. The construction scheme of gob-side entry retaining is depicted in Figure 4.3.

\section{Conclusion and Outlook}

From the research of 3414 split and two wing forward filling mining face in Xiezhuang coal mine, our study has accumulated experience for the promotion and application of filling mining technology in the future, and is a useful reference for other coal mines. The successful research of this subject not only solved the problem of environmental pollution, but also mined the coal under the village, and played an important role in guiding the safe pro- 
duction of the coal mine. Through the numerical simulation research of filling mining and non-filling mining, it was found that filling mining reduces the damage height of roof and floor, provides beneficial enlightenment to the mining method of the mine with water inrush risk, creates good social benefits, and has a good promotion value.

\section{References}

1. Cha Jianfeng. Study on the basic problems of subsidence control in gangue filling mining (China University of Mining and Technology, Chinese 2008)

2. Miao Xiexing, Zhang Jixiong, Journal of Mining and Safety Engineering, 04, 82 (2007)

3. Dai Huayang, Guo Junting, Yan Yueguan, Li Peixian, Liu Yisheng, Journal of China Coal Society, 39:08, 1602 ( 2014,)

4. Xie Shengrong, Zhang Guangchao, He Shangshen, Sun Yunjiang, Li erpeng, Yang lvgang, Xie Guoqiang, Journal of China Coal Society, 39:12, 2362 (2014)

5. Baiyi Li, Hao Yan, Jixiong Zhang, Nan Zhou, A new approach , 247 ( 2020) 